\title{
Increasing Accessibility in a Peer Assisted College Support Program for Students with Autism in Higher Education
}

\author{
Debra L. Cote ${ }^{1, *}$, Erica Howell ${ }^{1}$, Shannon L. Sparks², Malia Kasai ${ }^{1}$ \\ ${ }^{1}$ Department of Special Education, California State University, Fullerton, 92831, California, United States \\ ${ }^{2}$ Department of Special Education, Rehabilitation \& Counseling, California State University, San Bernardino, 92407, California, \\ United States
}

Received August 25, 2020; Revised October 16, 2020; Accepted October 25, 2020

\section{Cite This Paper in the following Citation Styles}

(a): [1] Debra L. Cote, Erica Howell, Shannon L. Sparks, Malia Kasai, "Increasing Accessibility in a Peer Assisted College Support Program for Students with Autism in Higher Education," Universal Journal of Educational Research, Vol. 8, No. 12, pp. 6439-6444, 2020. DOI: 10.13189/ujer.2020.081209.

(b): Debra L. Cote, Erica Howell, Shannon L. Sparks, Malia Kasai (2020). Increasing Accessibility in a Peer Assisted College Support Program for Students with Autism in Higher Education. Universal Journal of Educational Research, 8(12), 6439-6444. DOI: 10.13189/ujer.2020.081209.

Copyright $\bigcirc 2020$ by authors, all rights reserved. Authors agree that this article remains permanently open access under the terms of the Creative Commons Attribution License 4.0 International License

\begin{abstract}
Transitions from high school to an institution of higher education (IHE) can be compromised for young individuals with disabilities. Markedly, students with autism spectrum disorder (ASD) who attend college encounter unique challenges. These include aspects related to social contexts, anxiety, scheduling, relationships, organization, self-disclosure, meeting deadlines, communication, friendships, isolation, decision making, and goal setting. In order to meet this need, California State University, Fullerton offers the peer assisted college support program (PACS) to students with ASD enrolled at the university. PACS is a peer supported mentoring model that assists culturally and linguistically diverse students with ASD in navigating the college campus [1]. The aim of this paper is to provide a description of the PACS program at California State University, Fullerton as originally designed and then demonstrates how revisions were decided upon and implemented in light of participant and faculty feedback. A previous report highlighted the program structure and noted the short-term and long-term impacts [1]. Information gathered from the program identified programmatic barriers; reflections and conclusions resulted in program revisions. Current enhancements include a newly revised online framework that is easily accessible and maintainable. Program outcomes, sustainable resources, timeline protocols, collaborative university/district partnerships, and
\end{abstract}

guidelines are presented.

Keywords Autism, College Supports, Peer Mentoring

\section{Introduction}

In the United States, over a half million children with Autism Spectrum Disorder (ASD) finish secondary school (i.e., 44-45\%) and enter institutions of higher education (IHE) [2], [3]. The numbers of students with ASD earning degrees are increasing [4]. Data suggest one fourth to one third of students with ASD attend post-secondary school between two and six years after graduation [5]. Transitions for students with and without disabilities can be challenging, but particularly for individuals on the autism spectrum [6], [7]. A transition from secondary school to an IHE can leave students on the autism spectrum overwhelmed with all of the complexities of navigation [8]. Many students with ASD have the potential to do well in IHEs because of their above average intellectual abilities; however, they need some type of support [8]. Transitions go better when individuals can navigate issues related to college preparation such as academic and non-academic supports [9], disability disclosure/registration for services 
[10], adjusting to new structures, routines, schedules [11], peer acceptance, group connectedness, social interactions [12], [7], and/or rejection due to repetitive behaviors or interests [8], [13].

Researchers stress the importance of developing college programs that support the individual unique needs of postsecondary students with ASD [2], [5], [14], [15], [16], particularly issues related to class schedules, organization, meeting timelines, anxiety, stress, and isolation influence student success or failure [17]. Often students with ASD may not self-disclose and seek the educational/social support offered by disability support services, until after a problem surfaces inside or outside the classroom [15], [8]. Interestingly, Newman [18] found $63 \%$ of students who received special education services in high school and transitioned to postsecondary school did not believe they had a disability. A mere $24 \%$ of students with ASD identified themselves as someone with a disability and 36\% sought help at their college [18]. Without ongoing supports, results indicate these individuals can become depressed or anxious further withdrawing and/or dropping out of college [8].

\section{Meeting Diverse Needs in Structured Program Guidelines}

Students who attend California State University Fullerton (CSUF) come from diverse schools across the various districts. The institution ranks far above the national average in ethnic diversity [19]. To meet the demands of diverse learners with ASD, an intramural grant was awarded to a faculty member affiliated with the California State University, Fullerton (CSUF) Center for Autism and the Peer Assisted College Support (PACS) Program began in 2013 [1]. The program aims to support a smooth college transition for those diagnosed with ASD. PACS curriculum was developed by a CSUF faculty member, student researcher, and CSUF students with autism as consultants. The curriculum has been revised several times as each semester PACS partners (i.e., mentees/mentors) provide input on what should be added or removed [1].
The PACS program lasts for one semester; eight module topics are discussed over the course. Partners meet twice a month for $1 \frac{1}{2}-2$ hours at a mutually agreed upon campus location (e.g., Starbuck's, library, Titan Student Union, food court). Meeting on campus was intentional as Center faculty found partners were introduced to upcoming social activities (e.g., movie night, bowling) via posters or students handing out fliers and provides support for campus navigation. At the start of each meeting, students complete an ice breaker activity that helps promote interactions and increase partner comfortability. The PACS mentor leads the discussion. Topics of discussion can be seen in Table 1.

Partners in the program consist of a student with ASD and a veteran (e.g., $2^{\text {nd }}, 3^{\text {rd }}$ year) CSUF student who has experienced success at the college level. The goal is for incoming students to utilize the volunteer peer mentor as a resource, in addition to the supports provided by CSUF Disability Support Services (DSS). PACS mentors apply for the position through the Center for Autism and come from all disciplines; however, the majority major in Communicative Disorders, Special Education, and Child and Adolescent Studies. Some mentors have a personal connection to ASD (e.g., family member) or work part time with children with ASD (i.e., applied behavior analysis therapist, intervention behavioral therapist). Typically, PACS mentors return to the program and continue working with new participants. Their connection to the Center for Autism, volunteering as a mentor, has provided practical proficiency working with various populations plus increased their skillsets working with individuals on the autism spectrum. The mentors share information mentees need to navigate university life (e.g., student club organizations, study/organization habits) and are responsive to mentees' inquiries. For example, one mentee wanted to observe a classroom to see what the course was like prior to enrolling. A request was made and the pair were able to attend a class session. Unique to PACS is the peer to peer support. Howell and Cote [1] noted "PACS offers more comprehensive assistance by helping students acquire a variety of necessary skills, attitudes and behaviors" (p.222).

Table 1. PACS Topics for Discussion

\begin{tabular}{|l|l|l|}
\hline Module & Topic & Overview of: \\
\hline One & PACS Overview & Program and college campus \\
\hline Two & CSUF Navigation & Website and student clubs \\
\hline Three & Housing & Campus living options \\
\hline Four & Tips & Procedures for when emailing and approaching professors/instructors during office hours \\
\hline Five & Schoolwork & Balance - goal setting \\
\hline Six & Future & Exploring future options \\
\hline Seven & Finals & Preparation \\
\hline Eight & Break & Off campus activities \\
\hline
\end{tabular}




\section{PACS Anticipated Outcomes}

As PACS mentees increase their comfort levels interacting with peers and faculty on campus, one hopes that social and academic success will increase as well. One indicator of this outcome is the pattern of PACS mentees who have returned to the Center, serving as PACS mentors to incoming students with ASD. As mentees, their experiences have moved them to present with Center faculty about PACS. They become advocates for the program and assist parents and students in taking advantage of the supports offered at the college. Center faculty have found the mentees act of 'paying it forward' one of the greatest rewards in overseeing the program.

Center faculty desire to increase the program and recruitment of PACS participants. One small limitation to participation has been student follow through once an interest was expressed. That is, participants met with Center faculty, sat through the training, and were matched with a PACS mentor. However, they did not follow through on the next steps. The Center can easily support a higher frequency of students with autism transitioning to the university as there are many students willing to serve as mentors.

This paper provides comprehensive information on program enhancements that increased accessibility to CSUF participants. Changes included creating an accessible online community, electronic modules/activities, application processes, on-going assessment, training materials for mentors and mentees, protocols for recruitment and timelines, and procedures for collaborating with district/university partners.

\section{History of Peer Assisted College Support}

PACS is a free mentoring program supports incoming first and second semester students with ASD in navigating the college campus [1]. All students registered with CSUF's Office of Disability Support Services (DSS) attend a new student orientation, usually with parents, and learn about many supports/services that the university offers. PACS targets students who have registered with CSUF's Office of Disability Support Services and provided evidence verifying ASD. Interested students meet with the Center for Autism faculty and learn about PACS. Additionally, Center directors highlight PACS at university events and when meeting with district partners raising awareness of the program.

Each year, programmatic barriers are assessed and common themes around time logistics for PACS participants/directors and the costs associated with creating hard copies of the curriculum were consistently identified. In response to this need, faculty decided to create a sustainable online program that could easily be replicated by other universities.

\section{Expanding PACS}

As the program grew, we were faced with the need to move forward with an online PACS community. The anticipated likely benefits of convenient access to the Titanium Community were: (1) increase/improve communication with faculty, (2) community for PACS participants, (3) electronic fillable pdfs for all module topics and activities, (4) capacity to regularly update information, (5) quickly respond to emerging issues or needs, (6) links to pre-post surveys, (7) online mentor application and recruitment process, (8) develop partnerships between universities and schools/districts, (9) platform to house materials, and (10) enhance procedures and protocols.

An element of the current PACS program is a hard copy packet/binder (i.e., one-inch plastic binder with dividers) with the eight topics of discussion and university resources. However, the online PACS model enables participants to access curriculum in a familiar format (i.e., Titanium Community) through the use of modules/activities, and the ability to provide feedback on the bi-weekly module topics, and coordinate meeting times/dates. Currently, faculty regularly check-in with mentors or mentees (e.g., face to face, FaceTime, phone, Zoom). The complexity of faculty trying to meet everyone's class/work schedule made it challenging. The online community provides a synchronous meeting place for pairs and faculty to share and schedule dates/times for check-ins and supports.

\section{Electronic Resources}

All module topics and activities were converted from word documents to fillable pdf versions. Both PACS mentors and mentees complete the module activities and upload them to the Titanium community every two weeks instead of at the end of the semester. What is unique to the online program is an opportunity for participants to provide feedback in a timelier manner. Prior to the online conversion, participants provided feedback/edits post completion of the program. This change allows faculty to gather feedback throughout the course of the semester and encourages pairs to submit suggestions while content is fresh in their minds.

\section{Protocols for Recruitment}

A benefit of the Center's collaboration with Disability Support Services is recruitment for PACS participants. Protocols assist with spring and fall recruitment. Typically, the number of fall participants exceeds spring enrollment. Following new student orientations in the fall and spring, a Gaming with PACS event is held. The purpose of this event is to provide information about PACS for students with ASD who are interested in participating in the program. 
During this event, games are played and a continental breakfast is served (e.g., juice, muffins, fruit). Prior PACS mentors and mentees attend the event and share their experiences.

After the Gaming with PACS event, the PACS director meets with students who are interested in participating as a mentor and mentee to answer questions. Students have the option to participate in PACS and a related research study examining program efficacy. Students who want to participate in the research component provide their consent per the IRB protocols.

\section{Mentor Application Process}

A streamlined online application process was put into place. The Center for Autism is composed of two Cores: the Applied Developmental Core and the Education Core. The PACS program is housed in the Education Core. The Education Core promotes the PACS program through social media, Department of Special Education courses, and university student forums. Applications can be found on the website and social media sites. Requirements for mentors include a GPA of 3.0 or higher and enrollment in an undergrad/graduate program. Additional expectations include: (a) interview with a PACS faculty member (i.e., PACS director/Autism Center associate director), (b) complete PACS mentor training, (c) review curriculum/content, and (d) register as a student associate with the Center for Autism Education Core (i.e., sign up for the specific three-unit course). Center for Autism faculty interview potential applicants, review transcripts/grades/recommendations and share overall Center expectations.

PACS mentors volunteer hundreds of hours per semester to facilitate success for students with ASD on campus and in the community. Additionally, mentors attend Center sponsored activities that are open to families and children in the community. Most mentors are from the undergraduate programs and are asked to return the following semester.

\section{PACS Training}

PACS requires mentors and mentees to receive trainings. Initially, these trainings were one hour in-person meetings with the PACS director at the beginning of the summer. Transitioning the training to an online format provided increased accessibility and decreased time spent coordinating trainings with each participant.

The mentor's training provides information on characteristics related to ASD, program expectations, curriculum, online resources and tools, videos, discussion board, and protocols. Mentees training contains information about DSS and university supports, program expectations, curriculum, online resources and tools, videos, discussion board, and protocols. The online community houses additional tools that foster a supportive environment and enhances collegiate success (e.g., study tools). While some of the PACS training is similar, mentees are provided with ancillary information that addresses the exceptional needs of individuals with ASD and their mentorship role. Faculty attempt to partner individuals with similar interests and traits. This proactive approach facilitated better communication/collaborations and understanding of individual support needs. Cai and Richdale [15] stressed, "Higher education institutions may expect to enroll more students with ASD in the coming years; meeting the needs to this growing population will be extremely challenging if these students' support needs are not understood and provided" (p. 40).

\section{Methods}

Researchers noted the importance of higher education mentorship programs providing assistance for students with ASD [20]. A key aspect of PACS is the program evaluation that occurs each semester. At the beginning of the semester, the PACS director and program participants exchange contact information about their preferred manner for communicating (e.g., cell number, FaceTime, text, phone, email). The director consistently checks in with mentors and mentees to gauge the appropriateness of the partnership, the program's ability to meet individual expectations, to learn if biweekly meetings are happening, and if the module timeline is effectual.

Furthermore, each participant, who consents to the research study, completes an exit interview and post-survey measure. The director asks participants their overall observations of the program and scribes notes. The post-survey data plus additional notes guide the PACS review team when making edits/revisions. Post-survey questions investigate the PACS program's effectiveness in facilitating a successful transition to CSUF for students with ASD. Further, survey data solicit participant perceptions of the program's effectiveness in reducing barriers in higher education for students with ASD. Each module is rated according to how helpful it was by the mentor and the mentee, and the interview gathers thorough information on the benefits and needs of the curriculum. A sample survey question asks 'How helpful was the discussion on emails, phone calls, and effectively using office hours?' Responses include: very helpful, somewhat helpful, not sure, somewhat helpful, and completely unhelpful. There is an option to indicate if the pair did not complete the module activity.

\section{Community Outreach}

An additional avenue of recruitment to on-campus efforts relates to community outreach. The PACS director 
emails local schools/districts to inform them about PACS. Teachers and administrators then have the ability to share about PACS with students with ASD and their parents who are transitioning to CSUF. Often, district partners call center faculty to inquire about PACS, seeking resources to share with students and parents. During the school year, districts have bussed students to campus to spend the day learning about PACS, hearing from previous PACS participants and learning about DSS services. DSS faculty also attend these events and share the process for receiving services and meeting criteria for DSS eligibility. Collaboration between universities and local high schools is an important component in offering transition support. As the system shifts, "the student will be leaving the public-school system, which offers services on an entitlement basis, and entering an adult service system that operates on the basis of eligibility" [21], p.81.

The outreach to schools/districts, staff, and parents is a proactive approach so that students with ASD and parents realize the need to advocate for supports prior to entering higher education and encountering barriers. Feinman and Schmalacker [22], (p.1) emphasized, "Encouraging students to advocate for supports that will assist in a smooth transition to college may lead to great success and retention. An important skillset to develop prior to the transition is self-advocacy."

\section{Materials}

The PACS curriculum contains content organized in bi-weekly modules. The curriculum was developed from research identifying barriers in higher education for students with ASD and needed supports in addition to feedback from CSUF students on the autism spectrum. Each module includes an agenda, goal, space for documentation, notes, future planning and reminders. Module one overviews the campus setting and encourages the pair to complete the self-guided campus tour. Partners discuss what they hope to gain from participating in PACS and what they want to learn from each other. The second module highlights navigating the campus website (e.g., email, academic advising, online IT help), effective study habits (i.e., steps to study skills), organizing class materials, and managing time. Ways to get involved on campus are examined next. Mentees learn about the numerous student organizations/campus clubs, pick a few of interest and contact the officers. Survey data suggest the module on communicating with faculty (i.e., emails, phone calls, face to face) is particularly helpful. Another module assists mentees in balancing schoolwork with personal interests and activities including practicing goal setting. PACS mentors facilitate a meeting about career exploration utilizing the campus online resources. The last two module topics examine study methods in preparation for finals and ideas on what to do over the semester break. The semester ends with pairs meeting on campus for pizza and bowling.

\section{Conclusions and Recommendations}

Center for Autism Education Core faculty found it important that PACS is aligned with the University's Mission and Goals (i.e., provide high impact practice, assisting in the retention and success rate of underserved populations, expand partnerships with local school districts). In order to better serve our students and respond to PACS program feedback, several goals were established. The first goal centered on examining the PACS curriculum in order to provide easier access for PACS participants (i.e., mentors, mentees). In response, PACS was converted to an electronic format that increased accessibility in the program [1]. The second goal involved the collaboration with other universities so that similar supports can be developed for their students with ASD. In response to these efforts, an additional university in southern California has adopted the program and adapted some pieces of the curriculum to the specific campus so that faculty from multiple universities are co-investigators on program effectiveness. The PACS program director and partner university faculty worked together to ensure fidelity of implementation. This collaboration suggests the ability of PACS to meet the needs of students with ASD in neighboring universities.

Clearly, the PACS program demonstrates that IHEs can offer sustainable and low-cost supports to students with ASD. Furthermore, these supports have more utility when offered in an online accessible format.

\section{REFERENCES}

[1] Howell, E., Cote, D., "The peer assisted college support program: Supporting students with autism spectrum disorder in the university setting." DADD CEC Online Journal, http://www.daddcec.com/uploads/2/5/2/0/2520220/dec2_20 15_doj_2.pdf. (accessed Jul. 5, 2020).

[2] Alverson, C. Y., Lindstrom, L. E., Hirano, K. A., "High school to college transition experiences of young adults with autism," Focus on Autism and Other Developmental Disabilities, vol. 34, no. 1, pp. 52-64, 2019. DOI: $10.1177 / 1088357615611880$.

[3] Jackson, S., Hart, L., Volkmar, F. R., "College experiences for students with autism spectrum disorder," Journal of Autism and Developmental Disorders, vol. 48, pp. 639-642, 2018. DOI: 10.1007/s10803-018-3463-7.

[4] Sanford, C., Newman, L., Wagner, M., Cameto, R., Knokey, A. M., Shaver, D., "The post-high school outcomes of young adults with disabilities up to 6 years after high school: Key findings from the National Longitudinal Transition Study-2 (NLTS2)." IES, https://ies.ed.gov/ncser/pubs/20113004/pdf /20113004.pdf. (accessed Jul. 5, 2020). 
[5] Bouck, E. C., Park, J., "Exploring post-school outcomes across time out of school for students with autism spectrum disorder." Education and Training in Autism and Developmental

Disorders,http://www.daddcec.com/uploads/2/5/2/0/252022 0/etadd_september_53_3.pdf. (accessed Aug. 19, 2020).

[6] Forte, S., Haray, A., "Transition readiness for an individual with autism spectrum disorder." Autism Spectrum News, https://autismspectrumnews.org/transition-readiness-for-anindividual-with-autism-spectrum-disorder/. (accessed Aug. 20, 2020).

[7] Zager, D., Alpern, C., "College-based inclusion programming for students with autism," Focus on Autism and Other Developmental Disabilities, vol. 25, no. 3, pp. 151-157, 2010. DOI: 101177/1088357610371331.

[8] White, S. W., Ollendick, T. H., Bray, B. C., "College students on the autism spectrum: Prevalence and associated problems," Autism: The International Journal of Research and Practice, vol.15, no. 6, pp. 683-701, 2011. DOI:10.1177/1362361310393363.

[9] Timmerman, L. C., Mulvihill, T. M. "Accommodations in the college setting: The perspectives of students living with disabilities." The Qualitative Report, http://nsuworks.nova. edu/tqr/vol20/iss10/5. (accessed on Aug. 2, 2020).

[10] White, S. W., Elias, R., Capriola-Hall, N. N., Smith, I. C., Conner, C. M., Asselin, S. B., Howlin, P., Getzel, E., Mazefsky, C. A., "Development of a college transition and support program for students with autism spectrum disorder," Journal of Autism and Developmental Disorders, vol. 47, no. 10, pp. 3072-3078, 2017. DOI:10.1007/s10803-017-3236-8.

[11] Accardo, A. L., Kuder, S. J., Woodruff, J., "Accommodations and support services preferred by college students with autism spectrum disorder," Autism, vol. 3, no. 1, pp. 1-10, 2018. DOI: 10.1177/1362361318760490.

[12] Nevill, R. E. A., White, S. W., “College students' openness toward autism spectrum disorders: Improving peer acceptance," Journal of Autism and Developmental Disorders, vol. 41, no. 12, pp.1619-1628, 2011. DOI: 10.1007/s10803-014-2195-6.

[13] Gül Kahveci, Nergüz Bulut Serin, "Shaping Vocal Stereotypy in Autism Spectrum Disorder: A Non-aversive Communication Teaching Technique," Universal Journal of Educational Research, vol. 7, no. 6, pp. 1448 -1457, 2019. DOI: 10.13189/ujer.2019.070612.
[14] Brody, A., "Meeting the needs of youth in transition: Recommendations for systems reform." Autism Spectrum News,

https://behavioralhealthnews.org/meeting-the-needs-of-yout h-in-transition-recommendations-for-systems-reform/. (accessed on Jul. 17, 2020).

[15] Cai, R. Y., Richdale, A. L., "Educational experiences and needs of higher education students with autism spectrum disorder," vol. 46, pp 31-41, 2016. DOI: 10.1007/s10803-015-2535-1.

[16] Cohen, M. R., Oppenheimer, E. (2013). "Finding the best fit: Exploring college and vocational options." Autism Spectrum News, https://www.autismspectrumnews.org/wpcontent/uploads/2018/05/ASN-Winter2013.pdf.(accessed Jul. 3, 2020).

[17] Kuder, S. J., Accardo, A.,"What works for college students with autism spectrum disorder," Journal of Autism and Developmental Disorders, vol. 48, pp. 722-731, 2018. DOI: 10.1007/s10803-017-3434-4.

[18] Newman, L., Wagner, M., Knokey, A. M., Marder, C., Nagle, K., Shaver, D. Wei, X., Cameto, R., Conreras, E., Ferguson, K., Greene, S., Schwarting, M., SRI International., Buckley, J. A. "The post-school outcomes of young adults with disabilities up to 8 years after high school: A report from the National Longitudinal Transition Study-2 (NLTS2) (NCSER Report No. 2011-3005).” IES. https://ies.ed.gov/n cser/pubs/20113005/. (accessed on July 6, 2020).

[19] College Factual, "Cal State Fullerton student population: Who goes here?" College Factual.https://www.collegefactu al.com/colleges/california-state-university-fullerton/. (accessed on June 11, 2020).

[20] Sarrett, J. C., "Autism and accommodations in higher education: Insights from the autismcommunity," Journal of Autism and Developmental Disorders, vol. 48, pp. 679-693, 2018. DOI 10.1007/s10803-017-3353-4.

[21] Gibbons, M. M., Hyfantis, J., Cihak, D. F., Wright, R., Mynatt, B., "A social-cognitive exploration of the career and college understanding of young adults with intellectual disabilities," ASCA Professional School Counseling, vol. 19, no. 1, pp. 80-91, 2015. DOI: 10.5530/1096-2409-19.1.80.

[22] Feinman,S., Schmalacker, C., "Accommodations for students in the higher education environment." Autism Spectrum News, https://autismspectrumnews.org/accommo dations-for-students-in-the-higher-education-environment/. (accessed on August 20, 2020). 